\title{
Towards the Implementation of Quality of Life Monitoring in Daily Clinical Routine: Methodological Issues and Clinical Implication
}

\author{
Johannes Giesinger Georg Kemmler Verena Meraner Eva-Maria Gamper \\ Anne Oberguggenberger Barbara Sperner-Unterweger Bernhard Holzner
}

Department of Psychiatry and Psychotherapy, Innsbruck Medical University, Austria

\author{
Key Words \\ Breast neoplasms - Quality of life - Computers . \\ Monitoring · Review
}

\section{Summary}

Quality of life (QOL) has become a widely used outcome parameter in the evaluation of treatment modalities in clinical oncology research. By now, many of the practical problems associated with measuring $\mathrm{QOL}$ in clinical practice can be overcome by the use of computer-based assessment methods. QOL assessment in oncology is dominated by two measurement systems, the FACT scales and the EORTC QLQ-C30 with its modules. The amount of human resources required to implement routine data collection has been reduced significantly by advanced computer technology allowing data collection in busy clinical practice. Monitoring of QOL can contribute to oncologic care by facilitating detection of physical and psychological problems and tracking the course of disease and treatment over time. Furthermore, the integration of screening for psychosocial problems into QOL monitoring contributes to the identification of patients who are in need of psychooncologic interventions. Computer-based QOL monitoring does not replace the direct physician-patient communication but enables to identify specific impairments and symptoms including psychological problems. Beyond clinical practice, QOL data can be used for research purposes and may help health care planners to determine those patient services that should be maintained or ones that should be developed.

\author{
Schlüsselwörter \\ Brustkrebs · Lebensqualität · Computer · Monitoring · \\ Review
}

\section{Zusammenfassung}

Lebensqualität (LQ) hat sich in der klinisch-onkologischen Forschung zu einem häufig verwendeten Outcome-Parameter bei der Evaluation von Behandlungsstrategien entwickelt. Inzwischen können viele praktische Probleme bei der LQ-Erhebung in der klinischen Routine durch den Einsatz von computergestützten Erhebungsmethoden überwunden werden. Die LQ-Erhebung in der Onkologie wird von zwei Messsystemen dominiert, den FACT-Skalen und dem EORTC QLQ-C30 mit seinen Modulen. Der Personalaufwand für die Implementierung von routinemäßiger Datenerhebung wurde durch fortgeschrittene Computertechnologie wesentlich reduziert, sodass diese inzwischen auch im arbeitsreichen klinischen Alltag möglich ist. LQ-Monitoring kann zur onkologischen Behandlung beitragen, indem es die Erfassung von physischen Symptomen und psychologischen Problemen erleichtert und den Krankheits- und Behandlungsverlauf zu verfolgen erlaubt. Zudem kann die Integration von Screening nach psychosozialen Problemen die Identifikation jener Patienten verbessern, die psychoonkologische Behandlung benötigen. Computergestützes LQ-Monitoring dient nicht dazu, den direkten Arzt-Patienten-Kontakt zu ersetzen, ermöglicht jedoch die Identifikation spezifischer Beeinträchtigungen und Symptome einschließlich psychischer Probleme. Zusätzlich können die LQ-Daten für Forschungszwecke verwendet werden und als Entscheidungsgrundlage für die Ein- bzw. Weiterführung von Gesundheitsservices dienen.

\section{KARGER}

Fax +497614520714

Information@Karger.de

www.karger.com (c) 2009 S. Karger GmbH, Freiburg

www.karger.com/brc 


\section{Introduction}

Quality of life (QOL) has become a widely used outcome parameter in the evaluation of treatment modalities in clinical oncology research. Though the investigation of biomedical outcome such as disease-free survival or treatment toxicity are crucial issues, the importance of overall impact of cancer and its treatment on psychological, functional, and social health is emphasized [1, 2]. Groll et al. [3] even claim QOL and mental well-being to be the most important outcome in any illness. The concept of QOL stands for the subjective experience of physical, mental, and social health comprising physical symptoms and psychosocial functioning $[4,5]$. It is considered a major issue in the assessment of patient-reported outcomes (PRO) in oncologic patients. As a consequence, much effort was made over the last 20 years to establish valid and reliable instruments to assess QOL of cancer patients [6]. As a result of such research, several cancer-specific QOL instruments have been developed and validated, including the EORTC QLQ-C30 (European Organization for Research and Treatment of Cancer Quality of Life Core Questionnaire) developed by the EORTC Quality of Life Group [7] and the FACT-G (Functional Assessment of Cancer Therapy - General, [8]) and its various modules. In clinical trials, the main use of these questionnaires has been to provide an additional outcome measure to compare different oncologic treatment regimens, with the questionnaires usually being administered at different stages of the disease and at various times in the course of treatment.

QOL studies historically have been conducted with the expectation that in time health care providers would routinely incorporate measurements of QOL into clinical practice in order to improve individualized cancer treatment (e.g. symptom management) [9]. However, up to now this has been rarely implemented. Perceived barriers to incorporating routine assessments into clinical practice include providers' perceptions about utility and availability of instruments, methodological concerns, and logistic/practical considerations [10]. Many of the practical problems associated with measuring QOL in clinical practice are overcome by the use of new technologies giving rise to the hope that routine assessment of QOL in clinical practice will increase in the near future.

The aim of this paper is to provide an overview of issues relevant to the implementation of QOL monitoring in daily clinical routine consisting of both methodological as well as clinical aspects. Methodological considerations comprise QOL instruments and novel assessment methods as well as interpretational issues of QOL scores. Clinical issues deal with the impact of QOL monitoring on clinical care and screening for physical symptoms and psychooncologic treatment needs.

\section{QOL Research in Breast Cancer Patients}

Women with breast cancer represent the largest population of female cancer survivors [11]. High rates of curative treatment for localized disease and long-term overall survival are reported in these patients. It can therefore be argued that in this patient group research should not focus solely on the immediate effects of treatment, disease-free intervals, and survival rates. Another important aspect in this context is a differentiated knowledge of the long-term perspectives regarding levels of functioning and subjective well-being. In previous breast cancer studies, QOL served primarily as a means of evaluating somatic treatment concepts, for instance, when comparing different operative techniques - breast-conservation vs. mastectomy, or different chemo- and radiotherapeutic regimens. These studies, in which QOL assessment was an 'add on' to the clinical protocol, were primarily concerned with the shortterm effects of the therapies employed. A comprehensive review by Montazeri [12] enclosed 477 studies engaged in QOL research in breast cancer patients, which all focused on QOL outcomes and psychological distress in association with surgical procedures or systemic therapies. It can be conveyed from these studies that QOL data can contribute considerably to clinical decision-making by providing valuable information on symptom burden and other treatment-related side effects, such as changes in body image and sexuality, from the beginning of treatment to follow-up. Furthermore, the weight of evidence suggests that QOL and psychological distress are good predictors for overall survival. However, there are still important issues that have not been targeted sufficiently in this realm of research, such as the evidence-based selection of treatments as well as evaluation of psychosocial interventions and of communication between patients and health care providers [12]. As breast cancer patients enjoy long survival periods today, future studies should include QOL issues, i.e. functional aspects and life satisfaction as a main focus.

\section{Methodological Issues in QOL Assessment}

\section{Instruments for the Assessment of QOL in Breast Cancer \\ Patients}

QOL assessment in oncology is dominated by 2 measurement systems, the FACT scales on the one hand and the EORTC QLQ-C30 with its modules on the other [12]. Both comprise a core questionnaire assessing major issues relevant to all oncologic patients and modules specific for certain patient groups or issues (e.g. patient information, satisfaction with care). The FACT-G and the QLQ-C30 cover physical, emotional, functional, and social aspects of QOL with a comparable number of questions. The latter includes also further subscales and individual items assessing cognitive functions, symptomatology, and financial impact of the disease. In previous research the domains of physical, emotional, and functional/role of the 2 
instruments showed acceptable comparability [13]. However, for the social domain serious discrepancies between the corresponding FACT-G and EORTC subscales were detected [14, $15]$, as the former focuses on social support while the latter measures social functioning.

For clinical applications (e.g. a clinical trial comparing the effects of 2 types of chemotherapy), both instruments should be, for the most part, equally suited. For QOL assessment in breast cancer patients, the FACT-G can be supplemented with the FACT-B (Breast) and the FACT-ES (Endocrine Symptoms). The FACT-B assesses additional physical symptoms relevant to breast cancer patients, aspects of body image, and worries, whereas the FACT-ES covers a range of hormonal symptoms common in patients undergoing endocrine therapy. The EORTC QLQ-BR23 [16] is an additional breast cancerspecific module for the QLQ-C30 comprising treatment side effects as well as important emotional and social issues.

\section{Computer-Based Assessment of QOL in Clinical Oncologic Routine}

Traditional paper- and pencil-based QOL assessment is connected with a considerable amount of time for the medical staff. Therefore, it is considered as crucial to assess data computer-based. Advanced computer technology allows a reduction of required human resources making the routine collection of data feasible in busy clinical practices [17-22]. Furthermore, it enables real-time QOL data analysis and presentation of results immediately to clinicians [23-25]. Several studies have shown that the use of computer technology is an acceptable and efficient method for obtaining self-reported information on QOL. These data are highly comparable to those collected by paper and pencil approaches [26, 27]. Despite an overall lack of computer experience, touch-screen computer surveys are also acceptable for older patients. This is well confirmed by concordant findings in the literature [17, $20,27]$. The clear and user-friendly presentation of the QOL results is essential for clinical practice. Velikova et al. [28] for example designed and used multiple small graphs presenting all results on a single page making it easy to identify QOL changes of cancer patients over time. Studies in which computer-based routine assessment of QOL in clinical practice was evaluated suggest some important benefits for the physicians, the patients, and their treatment: screening for potential health and/or psychosocial problems and prioritizing these, facilitating communication and shared clinical decision-making, monitoring changes or response to treatment, and changing and improving patient management [29]. An initial training session for all involved staff members is needed to demonstrate handling the software and to learn how to interpret QOL scales. In such a session, examples of individual QOL profiles and corresponding clinical data as well as adequate interventions should be discussed. A crucial point is to communicate that global QOL alone is an insufficient measure of patients' physical and psychological status. The repetition of training sessions in adequate intervals helps to improve the correct interpretation of the data including longitudinal charts and the interaction of different symptoms and functioning scales. Furthermore, despite the user friendliness of the software and the low degree of help needed, the computerized data collection needs to be supervised in the daily routine to guarantee gapless administration and to provide a contact person for possible questions concerning the questionnaires or the monitoring itself.

\section{Interpretation of QOL Scores and Changes}

In order to benefit from the new possibilities computer technology offers for collection, evaluation, and visualization of QOL data, physicians and other medical staff need a certain amount of guidance. This applies in particular to the interpretation of QOL data which, in contrast to clinical variables, are not very familiar to most medical users [9]. One possibility is to provide reference values for QOL scores, e.g. medians and percentiles for individual diagnostic groups. The QOL scores of a new patient can then be compared to these reference values. In a similar way normative QOL data can also be obtained from the general population to investigate long-term effects of cancer and its treatment [30].

In addition, changes in QOL within patients should also be considered. Various criteria for defining clinically relevant changes have been proposed. These may be broadly classified into 2 groups, anchor-based and distribution-based criteria [31]. Anchor-based criteria make use of additional information obtained from the patient (who is asked to rate the relevance of perceived changes in health status or well-being) or from the clinical context (e.g., a laboratory or physiological measure or a rating by the clinician). Comparison of this information with the actually measured differences on the QOL scale allows estimation of the so-called minimal important difference (MID), the threshold to be used to distinguish relevant changes from irrelevant ones. Distribution-based methods make use of the statistical distribution of the QOL data to derive threshold values for relevant changes. In oncology, MIDs have been established for various instruments of the FACIT system [32, 33] and for the EORTC QLQ-C30 [34], among others. Most of these MIDs have been derived for use with groups of patients rather than individual subjects. They should not simply be transferred to the case of an individual patient without further consideration [35]. For the EORTC QLQ-C30, suggestions have been made how MIDs may be modified in order to evaluate changes in the individual patient for monitoring purposes [36].

\section{Computer-Adaptive Testing (CAT)}

Another advantage of computer-based assessments is the possibility of implementing computer-adaptive testing (CAT). Because clinicians and researchers frequently request the minimum required number of questions to obtain the desired precision of measurement of a particular symptom such as fa-
Giesinger/Kemmler/Meraner/Gamper/ Oberguggenberger/Sperner-Unterweger/ Holzner 
tigue, pain, anxiety and depression the development of CAT has gained considerable importance. The basic idea of CAT is to tailor the questionnaire to the individual patient. Based on the responses to an item, it is calculated which item should be asked next to get the maximal information from the patient. CAT is based on item response theory (IRT) methods that allow to directly compare scores between persons even though they have answered different sets of items. Traditionally, to ensure compatibility of results, all participants in a study complete the same questionnaire. However, some questionnaire items may provide little information about the individual participant. For example, if a patient has answered that he cannot take a short walk there is no reason to ask whether he can take a long walk. Such items are inefficient and patients' compliance may be hampered if questions are viewed as irrelevant or even inappropriate. The administration of items proceeds until a predefined level of precision has been reached or until a predefined number of items has been asked. The advantages of CAT are: increased precision using the same number of items, questionnaire length can be adapted to each study or patient, reduced floor and ceiling effects, and noninformative questions can be avoided. Therefore, CAT can be considered a powerful way to improve measurement precision in research based on PRO. Because of the clear advantages of CAT, a number of research groups are developing CAT for measurement of QOL. The PROMIS project is developing CAT in and for use in the USA [37-40]. QualityMetric is another American group that has developed CAT measuring the impact of headache, rheumatoid arthritis, and osteoarthritis [39-41]. The EORTC study group on QOL is as well engaged in constructing a CAT version of the internationally widely used QOL core questionnaire QLQ-C30 [42].

\section{QOL Monitoring and its Implementation in Oncologic Care}

Monitoring of QOL can contribute to oncologic care by facilitating detection of physical and psychological problems and tracking the course of disease and treatment over time [9, 43]. Implementation into routine clinical practice may help to collect important information and to use the limited time of medical consultations more efficiently.

\section{Example of a Software Solution for QOL Monitoring}

The Computer-based Health Evaluation System (CHES) [44] is an elaborated software to assess PRO, such as QOL, in daily oncologic routine. CHES provides computerized assessment, calculation, and presentation of psychosocial and medical data. It is based on Java and provides a client-server solution (database, e.g. MySQL, SQL, oracle). Data is assessed by the patients themselves via Tablet-PC and can be supplemented by medical staff. Handling of the questionnaires is very easy, since e.g. font sizes and size of the buttons can be tailored to the capacities of certain patient groups (e.g. for elderly people). Results are presented as eye-catching graphs in real time, and a 'flag system' marks patients with clinically relevant problems. For ease of interpretation, the graphical flag system incorporates adjusted reference values and thresholds for changes over time in a way that can be quickly grasped. The graphical output links QOL to the course of disease and treatment, and in addition specific medical interventions can be easily incorporated. Furthermore, CHES provides a print module, a module for calculating basic statistics, a study monitoring module, and a data export/import interface for CIS-HL7 and SPSS. It can be adapted to the requirements of the user (e.g. patient data, assessment instruments, graphical presentation, print for medical records). As an add-on, the socalled CHES Questionnaire Builder, a software for the easy generating and editing of questionnaires for use on TabletPCs, was developed.

\section{Web-Based QOL Home Monitoring}

Extending QOL monitoring beyond the clinical setting is desirable to gain more complete knowledge on a patient's physical and psychosocial well-being. Web-based assessments are an approach to close significant gaps of longitudinal oncologic treatment evaluation. Especially in patients undergoing chemotherapy, home monitoring allows to cover time points of severe treatment burden, since it is known that symptom burden is most severe a few days after application of cytostatic drugs. Traditional assessments may therefore underestimate impairment in such patients. With regard to symptom management, home monitoring may lead to an improvement of future clinical care by extending the potential window for intervention. Home monitoring can also comprise an alert system notifying the medical staff if a patient exceeded certain cut-off scores in an assessment [45].

An outstanding example of web-based QOL monitoring in cancer patients was developed and implemented by Bush et al. [45] to measure short-term (dynamic) changes in QOL by employing frequent, brief, online QOL assessments and more extensive, monthly online assessments. This study showed high feasibility of the web-based methodology and yielded good patient compliance and high user satisfaction. Up to now, only very few outstanding cancer care centers are engaged in developing and implementing web-based home monitoring and evaluation technology (e.g. Memorial Sloan-Kettering New York, Fred Hutchinson Cancer Research Center Seattle).

\section{Impact of QOL Monitoring on Clinical Care}

Studies in which computer-based QOL monitoring in clinical practice was evaluated suggest some important benefits for the physicians, the patients, and their treatment: to screen for potential health and/or psychosocial problems and to prioritize these, to facilitate communication, to facilitate shared clinical decision-making, to monitor changes or response to treatment, to enhance patients' QOL and satisfaction with 
care, to change and improve patient management and treatment outcome [29].

In a recent study by Hilarius et al. [46], the implementation of computer-based QOL assessment in daily clinical oncology proved to increase the frequency of QOL issues discussed in patient-nurse interaction. Furthermore, significant improvement was observed in nurses' awareness of patients' level of functioning (daily activities), symptoms (pain), and the overall QOL. A further well-designed longitudinal study [47] focusing on the impact of routinely computer-based PRO assessment found that there were no differences between patients for whom PRO data was available to the health care team and patients for whom such information was not provided. This was true with regard to QOL, treatment satisfaction, and reduction of cancer needs. Only for patients being at least moderately depressed at baseline a significant reduction in depression over time was found in the group for which PRO data was provided.

As in the traditional physician-patient contact assessment of the full range of health-related problems in cancer patients is often impossible, a standardized measurement of patients' QOL offers an important add-on of collecting subjective information. It supports clinicians in identifying important problems for discussion during the limited time of the medical consultation [43, 48]. In 1992, Deyo et al. [49] already stated that routine assessment of QOL may lead to an increase in number of issues discussed during medical consultation and could be helpful in identifying unexpected functional or emotional problems. In this way, also the patient-physician communication about functional or psychosocial impairments can be improved. This was confirmed by more recent studies dealing with cancer patients. These studies suggested that feedback of health status data increased the frequency with which QOL issues that were less observable were discussed, led to an increasing detection of psychological morbidity and social problems, and facilitated doctor-patient communication [22, $26,43,50,51]$.

Studies demonstrate the advantages of the use of QOL information during encounters for patients, physicians, and the interaction between the two by providing useful information for developing a treatment plan and encouraging the patient to take an active role in decision-making processes [52] without lengthening the average consultation time [9, 51]. Having determined the feasibility and acceptability of QoL assessment, the question remained as to whether the use of computer-based assessment would result in any changes in medical treatment. There is disagreement in the literature regarding this issue. For example Velikova et al. [43] and Detmar et al. [51] only found an effect of routine QOL measurement on physician-patient interaction but not on medical decisionmaking nor on treatment outcome (e.g. relapse-free survival, survival, response rate) $[53,54]$. Within a randomized clinical trial, the software package CHES was evaluated regarding its feasibility and efficiency in daily clinical routine. Pa- tients undergoing chemotherapy at the oncologic outpatient unit of Kufstein County Hospital were randomly allocated to a control group and an intervention group. The intervention group filled in the EORTC QLQ-C30 at each visit, and their CHES-generated QOL profiles were used in physician-patient contact. In the control group, patients filled in the QLQC30, but QoL profiles were not available to the physicians. At each visit duration, patients' satisfaction, QOL and medical interventions were recorded. Preliminary results showed that QOL assessment and its graphical presentation with the help of CHES can be integrated in daily clinical oncologic practice and leads to an improvement of patients' satisfaction with care. Furthermore, QOL got better in the physical and the emotional domain, particularly for chemotherapy non-responders. In $17.4 \%$ of the visits, medical interventions (including treatment of symptoms such as pain, sleep disturbances, and constipation/diarrhea; further examinations, referral to psychooncologists) were initiated as a consequence of the interpretation and discussion of the QOL profiles in the intervention group. Detailed results are published elsewhere.

In summary, the routine assessment of QOL in clinical practice apparently enhances patient-physician communication and detection of somatic and psychosocial problems whereas the impact on patients' QOL, medical care, and treatment outcome (e.g. disease-free survival, overall survival) remains unclear.

\section{Integration of Screening for Psychooncologic Treatment Needs into QOL Monitoring}

Though many patients with a diagnosis of breast cancer will survive, facing a life-threatening disease still accounts for marked distress and life disruption for patients. This is especially true in the early phase of diagnosis and treatment, but remains across the course of cancer trajectory and into longterm survivorship [55, 56].

Psychosocial distress has long been identified as a significant issue for patients diagnosed with cancer. Studies showed that although one third to $45 \%$ of cancer patients are affected by psychological problems $[57,58]$, fever than $10 \%$ are referred to psychosocial care [59]. Clinically significant distress often goes unrecognized by medical staff members in clinical oncology settings $[60,61]$ and under-referred to mental health professionals [62]. Physicians are often too pressed for time to adequately inquire about patient distress [60], and patients, already struggling with the stigma of a cancer diagnosis, do not spontaneously talk about their distress. If psychological problems in oncologic patients stay undetected, they may become compounded resulting in multiple chronic problems associated with poorer mental health. The presence of heightened distress is associated with a number of negative consequences, including greater non-adherence to treatment recommendations [63], poorer satisfaction with care [60], diminished adaptation to live with the disease [64], and poorer QOL across multiple domains [65]. Many patients do not spontaneously 
disclose emotional difficulties during medical consultations [66]. Therefore, clinicians need to elicit this information through the use of appropriate instruments. Screening for psychosocial problems may identify patients who require referral and/or further assessment and contribute towards a more effective oncology service [67, 68].

In a recent study by Meraner et al. [69], a screening tool for psychooncologic treatment needs in breast cancer patients was developed. Such screening tools can easily be integrated in QOL monitoring allowing an improved detection of patients needing referral to an psychooncologist. Identification of highly distressed patients is the sine qua non for adequate interventions comprising educational approach, training in coping skills, challenging unhelpful thoughts, relaxation training, or psychopharmacological interventions.

\section{Conclusion}

As the majority of breast cancer patients can be treated with curative intent and therefore live for extended periods of time, assessment of QOL is of high importance not only in patients under treatment and in follow-up but also in long-term survivors. Several well validated and internationally used breast cancer-specific QOL assessment instruments are available. Emerging software packages such as CHES facilitate data collection not only within clinical trials but enable easy implementation of QOL monitoring in various clinical settings including in- and outpatient units. Although staff burden is considered as low for establishing computerized QOL assessments, initial training of all medical staff members involved is essential to assure correct and detailed interpretation and use of individual patient QOL profiles. The implementation of computer-based QOL monitoring does not replace direct physician-patient communication but allows to identify specific impairments and symptoms including psychological problems. As a consequence, it may also improve multiprofessional cooperation and integrate different medical and psychological treatment strategies into one comprehensive therapeutic concept with its focus on the individual needs of each patient. Beyond clinical practice, QOL data can be used for research purposes and may help health care planners to determine those patient services that should be maintained or ones that should be developed.

\section{Conflict of Interest}

The authors declare that they have no conflicts of interest.

\section{References}

1 Bottomley A, Aaronson Neil K: International perspective on health-related quality-of-life research in cancer clinical trials: the European Organisation for Research and Treatment of Cancer experience. J Clin Oncol 2007;25:5082-6.

2 Fayers P, Bottomley A: Quality of life research within the EORTC-the EORTC QLQ-C30. European Organisation for Research and Treatment of Cancer. Eur J Cancer 2002;38(suppl 4):S125-33.

3 Groll R, Warde P, Jewett M: A comprehensive systematic review of testicular germ cell tumor surveillance. Crit Rev Oncol Hematol 2007;67:182-97.

4 Dahl A, Mykletun A, Fossa S: Quality of life in survivors of testicular cancer. Urol Oncol 2005;23:193200.

5 Miyake H, Muramaki M, Eto H, Kamidono S, Hara I: Health-related quality of life after chemotherapy for advanced germ cell tumors: A comparison of standard-dose and high-dose chemotherapy. Int J Urol 2004;11:542-6.

6 Fayers P, Machin D: Quality of Life: Assessment, Analysis and Interpretation. Chichester, J. Wiley \& Sons, 2000.

7 Aaronson NK, Ahmedzai S, Bergman B, Bullinger M, Cull A, Duez NJ, Filiberti A, Flechtner H, Fleishman SB, de Haes JC: The European Organization for Research and Treatment of Cancer QLQ-C30: a quality-of-life instrument for use in international clinical trials in oncology. J Natl Cancer Inst 1993;85:365-76.

8 Cella DF, Tulsky DS, Gray G, Sarafian B, Linn E, Bonomi A, Silberman M, Yellen SB, Winicour P, Brannon J: The Functional Assessment of Cancer Therapy scale: development and validation of the general measure. J Clin Oncol 1993;11:570-9.
9 Velikova G, Booth L, Smith AB, Brown PM, Lynch P, Brown JM, Selby PJ: Measuring quality of life in routine oncology practice improves communication and patient well-being: a randomized controlled trial. J Clin Oncol 2004:22:714-24.

10 Davis K, Cella D: Assessing quality of life in oncology clinical practice: a review of barriers and critical success factors. JCOM 2002;9:327-32.

11 UK office for National Statistics: www.statistics. gov.uk/cci/nugget.asp?id=861, 2009.

12 Montazeri A: Health-related quality of life in breast cancer patients: a bibliographic review of the literature from 1974 to 2007. J Exp Clin Cancer Res 2008;27:32.

13 Holzner B, Bode RK, Hahn EA, Cella D, Kopp M, Sperner-Unterweger B, Kemmler G: Equating EORTC QLQ-C30 and FACT-G scores and its use in oncological research. Eur J Cancer 2006;42:316977.

14 Kemmler G, Holzner B, Kopp M, Dunser M, Margreiter R, Greil R, Sperner-Unterweger B: Comparison of two quality-of-life instruments for cancer patients: the functional assessment of cancer therapy-general and the European Organization for Research and Treatment of Cancer Quality of Life Questionnaire-C30. J Clin Oncol 1999;17:2932-40.

15 Holzner B, Kemmler G, Sperner-Unterweger B, Kopp M, Dunser M, Margreiter R, Marschitz I, Nachbaur D, Fleischhacker WW, Greil R: Quality of life measurement in oncology--a matter of the assessment instrument? Eur J Cancer 2001;37:234956.
16 Sprangers MA, Groenvold M, Arraras JI, Franklin J, te Velde A, Muller M, Franzini L, Williams A, de Haes HC, Hopwood P, Cull A, Aaronson NK: The European Organization for Research and Treatment of Cancer breast cancer-specific quality-oflife questionnaire module: first results from a threecountry field study. J Clin Oncol 1996;14:2756-68.

17 Taenzer PA, Speca M, Atkinson MJ, Bultz BD, Page S, Harasym P, Davis JL: Computerized quality-of-life screening in an oncology clinic. Cancer Pract 1997;5:168-75.

18 Carlson LE, Speca M, Hagen N, Taenzer P: Computerized quality-of-life screening in a cancer pain clinic. J Palliat Care 2001;17:46-52.

19 Wright EP, Selby PJ, Crawford M, Gillibrand A, Johnston C, Perren TJ, Rush R, Smith A, Velikova G, Watson K, Gould A, Cull A: Feasibility and compliance of automated measurement of quality of life in oncology practice. J Clin Oncol 2003;21:374-82.

20 Buxton J, White M, Osoba D: Patients' experiences using a computerized program with a touch-sensitive video monitor for the assessment of health-related quality of life. Qual Life Res 1998;7:513-9.

21 Bendtsen P, Leijon M, Sommer SA, Kristenson M: Measuring health-related quality of life in patients with chronic obstructive pulmonary disease in a routine hospital setting: Feasibility and perceived value. Health Qual Life Outcomes 2003;1:5.

22 Wright EP, Selby PJ, Crawford M, Gillibrand A, Johnston C, Perren TJ, Rush R, Smith A, Velikova G, Watson K, Gould A, Cull A: Feasibility and compliance of automated measurement of quality of life in oncology practice. J Clin Oncol 2003;21:374-82. 
23 Chang CH, Cella D, Masters GA, Laliberte N, O'Brien P, Peterman A, Shervin D: Real-time clinical application of quality-of-life assessment in advanced lung cancer. Clin Lung Cancer 2002;4:104-9.

24 Fortner B, Baldwin S, Schwartzberg L, Houts AC Validation of the Cancer Care Monitor items for physical symptoms and treatment side effects using expert oncology nurse evaluation. J Pain Symptom Manage 2006;31:207-14.

25 Fortner B, Okon T, Schwartzberg L, Tauer K, Houts AC: The Cancer Care Monitor: psychometric content evaluation and pilot testing of a computer administered system for symptom screening and quality of life in adult cancer patients. J Pain Symptom Manage 2003;26:1077-92.

-26 Taenzer P, Bultz BD, Carlson LE, Speca M, DeGagne T, Olson K, Doll R, Rosberger Z: Impact of computerized quality of life screening on physician behaviour and patient satisfaction in lung cancer outpatients. Psychooncology 2000;9:203-13.

27 Velikova G, Wright EP, Smith AB, Cull A, Gould A, Forman D, Perren T, Stead M, Brown J, Selby PJ: Automated collection of quality-of-life data: a comparison of paper and computer touch-screen questionnaires. J Clin Oncol 1999;17:998-1007.

28 Velikova G, Wright P, Smith AB, Stark D, Perren T, Brown J, Selby P: Self-reported quality of life of individual cancer patients: concordance of results with disease course and medical records. J Clin Oncol 2001;19:2064-73.

29 Higginson IJ, Carr AJ: Measuring quality of life: using quality of life measures in the clinical setting. BMJ 2001;322:1297-300.

- 30 Holzner B, Kemmler G, Cella D, De Paoli C, Meraner V, Kopp M, Greil R, Fleischhacker WW, Sperner Unterweger B: Normative data for functional assessment of cancer therapy--general scale and its use for the interpretation of quality of life scores in cancer survivors. Acta Oncol 2004;43:153-60.

31 Revicki D, Hays R, Cella D, Sloan J: Recommended methods for determining responsiveness and minimally important differences for patient-reported outcomes. J Clin Epidemiol 2008;61:102-9.

32 Cella D, Nowinski C, J.: Measuring quality of life in chronic illness: the functional assessment of chronic illness therapy measurement system. Arch Phys Med Rehabil 2002;83(12 suppl 2):S10-7.

>33 Yost K, Cella D, Chawla A, Holmgren E, Eton D, Ayanian J, West D: Minimally important differences were estimated for the Functional Assessment of Cancer Therapy-Colorectal (FACT-C) instrument using a combination of distribution- and anchorbased approaches. J Clin Epidemiol 2005;58:1241-51.

- 34 Osoba D, Rodrigues G, Myles J, Zee B, Pater J: Interpreting the significance of changes in healthrelated quality-of-life scores. J Clin Oncol 1998;16: 139-44.

-35 Crosby R, Kolotkin R, Williams G: An integrated method to determine meaningful changes in healthrelated quality of life. J Clin Epidemiol 2004;57: 1153-60.

36 Kemmler G, Zabernigg A, Gattringer K, Rumpold G, Giesinger J, Sperner Unterweger B, Holzner B: A new approach to combining clinical relevance and statistical significance for evaluation of quality of life changes in the individual patient. J Clin Epidemiol; in press.

37 Cella D, Gershon R, Lai J-S, Choi S: The future of outcomes measurement: item banking, tailored short-forms, and computerized adaptive assessment. Qual Life Res 2007;16(suppl 1):133-41.
38 Cella D, Yount S, Rothrock N, Gershon R, Cook K, Reeve B, Ader D, Fries James F, Bruce B, Rose M: The Patient-Reported Outcomes Measurement Information System (PROMIS): progress of an NIH Roadmap cooperative group during its first two years. Med Care 2007;45(5 suppl 1):S3-S11.

39 Ware John E Jr, Kosinski M, Bjorner Jakob B, Bayliss Martha S, Batenhorst A, Dahlof Carl GH, Tepper S, Dowson A: Applications of computerized adaptive testing (CAT) to the assessment of headache impact. Qual Life Res 2003;12:935-52.

40 Bjorner Jakob B, Chang C-H, Thissen D, Reeve Bryce B: Developing tailored instruments: item banking and computerized adaptive assessment. Qual Life Res 2007;16(suppl 1):95-108.

41 Ware JE Jr, Bjorner JB, Kosinski M: Practical implications of item response theory and computerized adaptive testing: a brief summary of ongoing studies of widely used headache impact scales. Med Care 2000;38(9 suppl):II73-82.

42 Petersen Morten A, Groenvold M, Aaronson N, Fayers P, Sprangers M, Bjorner Jakob B: Multidimensional computerized adaptive testing of the EORTC QLQ-C30: basic developments and evaluations. Qual Life Res 2006;15:315-29.

43 Velikova G, Brown JM, Smith AB, Selby PJ: Computer-based quality of life questionnaires may contribute to doctor-patient interactions in oncology. Br J Cancer 2002;86:51-9.

44 Holzner B, Zabernigg A, Kemmler G, Baier S, Kopp M, Sperner Unterweger B: Computerized assessment of quality of life in patients undergoing chemotherapy. Qual Life Res 2004;13:1523.

45 Bush N, Donaldson G, Moinpour C, Haberman M, Milliken D, Markle V, Lauson J: Development, feasibility and compliance of a web-based system for very frequent QOL and symptom home selfassessment after hematopoietic stem cell transplantation. Qual Life Res 2005;14:77-93.

46 Hilarius D, Kloeg P, Gundy C, Aaronson N: Use of health-related quality-of-life assessments in daily clinical oncology nursing practice: a community hospital-based intervention study. Cancer 2008;113:62837.

47 McLachlan SA, Allenby A, Matthews J, Wirth A, Kissane D, Bishop M, Beresford J, Zalcberg J: Randomized trial of coordinated psychosocial interventions based on patient self-assessments versus standard care to improve the psychosocial functioning of patients with cancer. J Clin Oncol 2001; 19:4117-25.

48 Passik S, Dugan W, McDonald M, Rosenfeld B, Theobald D, Edgerton S: Oncologists' recognition of depression in their patients with cancer. J Clin Oncol 1998;16:1594-600.

49 Deyo RA, Carter WB: Strategies for improving and expanding the application of health status measures in clinical settings. A researcher-developer viewpoint. Med Care 1992;30(5 suppl):176-86

50 Detmar SB, Aaronson NK: Quality of life assessment in daily clinical oncology practice: a feasibility study. Eur J Cancer 1998;34:1181-6.

51 Detmar SB, Muller MJ, Schornagel JH, Wever LDV, Aaronson NK: Health-related quality-of-life assessments and patient-physician communication: a randomized controlled trial. Jama 2002;288:3027-34.

52 Ganz PA, Moinpour CM, Cella DF, Fetting JH: Quality-of-life assessment in cancer clinical trials: a status report. J Natl Cancer Inst 1992;84:994-5.
3 Greenhalgh J, Meadows K: The effectiveness of the use of patient-based measures of health in routine practice in improving the process and outcomes of patient care: a literature review. J Eval Clin Pract 1999;5:401-16.

54 Espallargues M, Valderas JM, Jordi A: Provision of feedback on perceived health status to health care professionals: a systematic review of its impact. Med Care 2000;38:175-86.

55 Stanton A: Psychosocial concerns and interventions for cancer survivors. J Clin Oncol 2006;24:5132-7.

56 Edwards A, Hulbert-Williams N, Neal R: Psychological interventions for women with metastatic breast cancer. Cochrane database of systematic reviews 2008;3:CD004253.

57 Derogatis LR, Morrow GR, Fetting J, Penman D, Piasetsky S, Schmale AM, Henrichs M, Carnicke CL Jr: The prevalence of psychiatric disorders among cancer patients. JAMA 1983;249:751-7.

58 Zabora J, Brintzenhofeszoc K, Curbow B, Hooker C, Piantadosi S: The prevalence of psychological distress by cancer site. Psychooncology 2001;10:19-28.

59 Carlson LE, Bultz BD: Cancer distress screening. Needs, models, and methods. J Psychosom Res 2003; 55:403-9.

60 Holland JC: Update: NCCN practice guidelines for the management of psychosocial distress. Oncology 1999;13:459-507.

61 Payne DK, Hoffman RG, Theodoulou M, Dosik M, Massie MJ: Screening for anxiety and depression in women with breast cancer. Psychiatry and medical oncology gear up for managed care. Psychosomatics 1999;40:64-9.

62 Newport DJ, Nemeroff CB: Assessment and treatment of depression in the cancer patient. J Psychosom Res 1998;45:215-37.

63 Kennard BD, Stewart SM, Olvera R, Bawdon RE, O hAilin A, Lewis CP, Winick NJ: Nonadherence in adolescent oncology patients: preliminary data on psychological risk factors and relationships to outcome. J Clin Psychol Med Settings 2004;11:31-9.

64 Von Essen L, Larsson G, Oberg K, Sjoden PO: 'Satisfaction with care': associations with healthrelated quality of life and psychosocial function among Swedish patients with endocrine gastrointestinal tumours. Eur J Cancer Care (Engl) 2002; 11:91-9.

65 Skarstein J, Aass N, Fossa SD, Skovlund E, Dahl AA Anxiety and depression in cancer patients: relation between the Hospital Anxiety and Depression Scale and the European Organization for Research and Treatment of Cancer Core Quality of Life Questionnaire. J Psychosom Res 2000;49:27-34.

66 Fallowfield L, Ratcliffe D, Jenkins V, Saul J: Psychiatric morbidity and its recognition by doctors in patients with cancer. Br J Cancer 2001;84:1011-5.

67 Wright EP, Selby PJ, Gould A, Cull A: Detecting social problems in cancer patients. Psychooncology 2001;10:242-50.

68 Hawighorst-Knapstein S, Brueckner DO, Schoenefuss G, Knapstein P, Koelbl H: Breast cancer care: Patient information and communication as a preventive educational process. Breast Care 2006;1:375-8.

69 Meraner V, Giesinger J, Kemmler G, Taucher S, Hubalek M, Weber B, Rumpold G, SpernerUnterweger B, Holzner B: Development of a screening tool for the identification of psychooncological treatment needs in breast cancer patients. Psychooncology 2009; epub ahead of print. 